\title{
A formação socioeconômica da região Oeste de Santa Catarina - uma narrativa acerca de franjas e retalhos da identidade regional
}

The socioeconomic formation of the western region of Santa Catarinaa narrative about fringes and fragments of regional identity

\author{
Arlene Renk ${ }^{\star}$ \\ Silvana Winckler**
}

Palavras-chave:

Processos Socioeconômicos

Trabalho

Meio Ambiente do Trabalho

Keywords:

Socioeconomic Processes

Job

Work Environment
Resumo: O texto aborda as transformações socioeconômicas da Região Oeste Catarinense, enfatiza relacionalmente os processos sociais que construíram e seguem construindo os eventos econômicos na região. Mostra as heterogeneidades de processos, e a erosão da economia substantiva com a instituição da economia formal, a substituição das formas solidárias de trabalho pelo assalariamento e a consolidação desta. Aponta a transformação da agricultura e a instalação da agroindústria. Como não poderia deixar de ser, também o meio ambiente do trabalho, principalmente nas grandes indústrias, mostra a outra face de Jano, com o adoecimento e as lesões que afetam os trabalhadores. Por fim, registra-se o ingresso da mão de obra Kaingang e de haitianos e senegalês no contexto regional.

Abstract: The text deals with the socioeconomic transformations of the Western Region of Santa Catarina, emphasizing relationally the social processes that have built and continue to build the economic events in the region. It shows the heterogeneities of processes, and erosion of the substantive economy with the institution of the formal economy, the substitution of forms of solidarity for work and the consolidation of it. It points to the transformation of agriculture and the installation of agribusiness. Of course, the work environment, especially in large industries, shows the other side of Jano, with illness and injuries that affect workers. Finally, there is the entry of the Kaingang labor force and of Haitians and Senegalese workers in the regional context.

Recebido em 31 de maio de 2018. Aprovado em 24 de julho de 2018.

\section{Introdução}

Uma região não surge espontaneamente; mas, é construída processualmente, com avanços e recuos, deixando ilhas a serem incorporadas posteriormente. Nos discursos de seus mediadores, isto é, daqueles que falam pela região, aparenta ser homogênea. No entanto, diferentes forças contribuem para que se elabore heterogeneamente, como mosaico. A região (substantivada) pressupõe sempre uma história comum, que será fatalmente uma história entre outras. A invenção de uma tradição comum é o passaporte para a constituição da identidade regional.
Mas, afinal, de que região se trata? De modo provisório, podemos afirmar que se trata dos contornos do município de Chapecó, tal como foi criado em 1917. No entanto, uma região - seja ela qual for - não se define pelo contorno, pelos limites geográficos. Estes podem, sim, ser acionados para legitimá-la.

Entre todos os argumentos para a construção discursiva de uma região, um deles tem jogado papel preponderante: a história construída acerca daquele espaço e os usos daquela história. Este também parece ser o caso do Oeste Catarinense, quando se toma a colonização como marco zero e se desconsideram os grupos e as narrativas anteriores.

\footnotetext{
* Doutora em Antropologia Social pelo Museu Nacional - Universidade Federal do Rio de Janeiro (UFRJ). Professora da Unochapecó. E-mail: <arlene@unochapeco.edu.br>.

** Doutora em Direito pela Universidade de Barcelona. Professora da Unochapecó. E-mail: <silvanaw@unochapeco.edu.br>.
} 
Seja qual for a narrativa da história (ou a contrahistóriaquenarraa região),éinevitávelqueesta apresente múltiplos planos. Estes planos, no entanto, não se encaixam uns aos outros, obrigatoriamente, na suposta linearidade dos contornos. Vejamos o caso da geopolítica, com seus limites. No caso em questão, do atual Oeste Catarinense, as fronteiras administrativas do Império do Brasil, no século XIX, têm um recorte indefinido entre o Brasil e a Argentina, somente resolvido em 1895. Depois, na República, de leste e a norte, acentua-se o conflito referente aos limites internos entre Paraná e Santa Catarina, apenas clareados em 1916, após sucessivas disputas judiciais. A categoria "Oeste" foi precedida, até as duas primeiras décadas do Século XX, por "serra", termo utilizado para designar tudo o que se situasse na Região Oeste do planalto catarinense. Instituições ali inseridas, como as eclesiásticas, tinham sede fora de seus limites, quando não fora do estado catarinense. Nas primeiras décadas da colonização feita por agricultores oriundos do Rio Grande do Sul (século XX), o atendimento médico, os jornais que circulavam pelas colônias, o comércio para a banha, entre outros, eram recursos buscados naquele Estado.

Há, portanto, dificuldades em delimitarse o Oeste Catarinense ${ }^{1}$. Podemos trabalhar esse conceito por aproximação. Para não procurar a gênese da gênese, podemos tomar como ponto de partida a Lei de Terras, de 1850, e sua regulamentação, quando áreas são legalizadas nessa fronteira por serem terras de campo e campina: a Campina do Gregório, as terras do Goio-En e as fazendas de criar de Campo-Erê. As demais áreas, de mata, são desprezadas. Também em decorrência da Lei de Terras, na década de 1980 do século XIX instala-se a Colônia Militar de Chapecó, onde hoje estão localizados os municípios de Xanxerê e adjacentes (RENK, 2006).

Essas são as primeiras ocupações formalizadas, desde o ponto de vista da presença estatal. Outras narrativas são encontradas, aqui e ali, em fragmentos da escrita e da memória que contam a história da região, da qual esmiuçaremos alguns elementos referentes à formação socioeconômica.

\section{Terra e trabalho}

O trabalho foi elemento constitutivo dos modos de inserção social no Oeste Catarinense.
$\mathrm{O}$ que se entendia por trabalho e os critérios para afirmar-se se alguém trabalhava, ou não, constituíram-se em fatores de distinção e de discriminação (RENK, 2000).

As primeiras atividades mercantis de que temos registros, na região, estavam relacionadas ao transporte de gado vacum e muar entre o Rio Grande do Sul e o centro consumidor, localizado em São Paulo e Minas Gerais. Os animais eram conduzidos em tropas por cavaleiros, em geral paulistas.

$\mathrm{Na}$ ocasião da "descoberta dos campos de Palmas", no século retrasado, o tropeirismo abriu o caminho de tropas do Rio Grande do Sul para São Paulo. Ao longo da estrada, nasceram lugarejos e pontos de descanso. Mesmo entrando em declínio o chamado ciclo de tropeirismo, a atividade persistiu. Após a implantação da estrada de ferro São PauloRio Grande, parte do deslocamento era feito nesta.

Os tropeiros deslocavam-se de São Paulo ao Rio Grande do Sul, inicialmente a cavalo e mais tarde em trem, levando consigo os "apetrechos" (equipamentos de montaria e de cozinha) necessários para o retorno, quando transitavam por picadas e estradas precárias. A travessia das tropas pelo rio Uruguai era feita a nado, espetáculo apreciado pelos ribeirinhos. O destino era a feira de Sorocaba, onde os animais eram comercializados e destinados ao consumo e ao trabalho nas lavouras de café e nas minas de ouro.

A disponibilidade de terras de campo nos Campos de Palmas, onde se inseriu o atual Oeste de Santa Catarina, favoreceu o estabelecimento das fazendas de criar. As posses foram estimuladas como consequência da Carta Régia de 1808 e legalizadas com a Lei de Terras (1850). Havia interesse da monarquia e, posteriormente, do Império no povoamento dessa região para a contenção do avanço dos argentinos em território brasileiro. A abundância de erva-mate - espécie arbórea com ocorrência nas florestas ombrófila mista e estacional decidual, características na região - era o principal atrativo para os extrativistas. Ao mesmo tempo, essa ocupação servia como "missão civilizadora" destinada a catequizar e/ou expulsar os indígenas (RENK, 2006). 
Fazendas de criar estabeleceram-se nos Campos de Palmas (que abrangia todo o Oeste Catarinense e os municípios paranaenses e Palmas e Clevelândia) e do Erê, este mais ao oeste, dando origem a latifúndios. Iniciado o processo de imigrações de agricultores procedentes do Rio Grande do Sul, já nas primeiras décadas do século $\mathrm{XX}$, a dimensão territorial das fazendas destoaria do modelo de ocupação agrária regional. Nos parâmetros coloniais, as parcelas mediam 24 hectares, configurando pequenas propriedades.

Além da criação, em regime extensivo, de gado vacum para consumo humano e de muares para o trabalho, essas fazendas dispunham de invernadas para o descanso das tropas.

Os primeiros trabalhadores (assim considerados pela literatura) presentes na região estão representados na figura do serrano: "Fruto da revivescência do bandeirante e do cruzamento e recruzamento do português com o índio Tupi (mameluco), [...] tipo tradicional de gaúcho, ao qual se vincula por efeito da proximidade geográfica, criando características próprias" (BAVARESCO, 2005, p. 50). Acostumado à vida dura e às intempéries da natureza, dedicava-se ao trato com o gado, atividade essencial de integração das fazendas de criar aos mercados consumidores do Sudeste.

O estabelecimento das fazendas de criar ensejou conflitos com a população autóctone. Os enfrentamentos entre fazendeiros e indígenas foram frequentes e levaram ao confinamento destes em regiões mais afastadas (RENK, 2006) 2 .

$A$ atividade ervateira (corte e enfardamento em "raídos") envolveu, igualmente, população acostumada à vida sem conforto e aos obstáculos naturais. A figura do caboclo, presente nos relatos das disputas de divisas territoriais entre Paraná e Santa Catarina, é marcante na região por sua história e cultura. Praticava a agricultura de subsistência, criava porcos e galinhas para consumo próprio e possuía hábitos nômades. Não estabelecia relação de apropriação com a terra, tampouco pensava em acumular bens, "fazendo para viver". Sua forma de produzir e de consumir corresponde à noção de economia substantiva, baseada na domesticidade, retribuição e redistribuição, nos moldes descritos por Karl Polanyi (1980).

As concepções de terra dessa população nos levam Polanyi (1980), quando estudou sociedades chamadas arcaicas, nas quais a terra não consistia em mercadoria. Dos embates entre valores e práticas das sociedades arcaicas com os da sociedade de economia de mercado autorregulável, observa o autor, em A Grande Transformação, publicada originalmente em 1944, que "a história e a etnografia conhecem várias espécies de economia" (POLANYI, 1980, p. 60). A Economia de Mercado é apenas uma delas:

Uma economia de mercado deve compreender todos os componentes da indústria, incluindo o trabalho, terra e dinheiro. [...] Acontece, porém, que o trabalho e a terra nada mais são do que os próprios seres humanos nos quais consistem todas as sociedades, e o ambiente natural no qual elas existem. Incluí-los no mecanismo de mercado significa subordinar a substância da própria sociedade às leis de mercado. [...] O ponto crucial é o seguinte: trabalho, terra e dinheiro são elementos essenciais da indústria. Eles também têm que ser organizados em mercados e, de fato, esses mercados formam uma parte absolutamente vital do sistema econômico. Todavia, o trabalho, a terra e o dinheiro obviamente não (grifo do autor) são mercadorias. $O$ postulado de que tudo o que é comprado e vendido tem que ser produzido para a venda é enfaticamente irreal no que diz respeito a eles. Em outras palavras, de acordo com a definição empírica de uma mercadoria, eles não são mercadorias. Trabalho é apenas um outro nome para a atividade humana que acompanha a própria vida que, por sua vez, não é produzida para venda mas por razões da vida, não pode ser armazenada ou mobilizada. Terra é apenas outro nome para a natureza, que é produzida pelo homem. [...] A descrição do trabalho, da terra e do dinheiro como mercadorias é inteiramente fictícia. (POLANYI, 1980, p. 83-86).

Tratar da economia substantiva requer que se abordem aspectos da dinâmica cultural de 
grupos societários, nos quais o modo de vida está imerso (embedded) nas relações sociais (POLANY, $1980)^{3}$. Aqui entram em jogo os puxirões, a mútua ajuda e a partilha de bens comestiveis para posterior devolução. Os mutirões ou puxirões eram procedimentos de sociabilidade mediados pelo trabalho que aproximavam o ofício laboral a uma festividade. Quem recebia a ajuda deveria propiciar o almoço aos trabalhadores. Todos os membros da família se envolviam nos afazeres do dia de trabalho compartilhado. Retribuir a ajuda consistia em uma dívida moral a ser paga na primeira oportunidade. Insere-se aqui o que Marcel Mauss (2003), em $O$ Ensaio da Dádiva, nomina por obrigação moral: a de doar, receber e a de retribuir. Clássico é o exemplo da carne: quando alguém caçava ou abatia um animal, distribuía pedaços à vizinhança e à parentela, contando como certo que estas devolveriam oportunamente a carne fresca, sempre apreciada.

Outra prática que merece destaque é o uso da terra em sistema de faxinal. Os faxinais situavamse nas franjas da economia capitalista, adotando um modo de apropriação comum dos recursos naturais. Reuniamospequenossitiantesquecompatibilizavam o criatório com o plantio, respeitando a floresta. Era um sistema compatível com áreas anchas, que se viu reduzido e ameaçado com a colonização, de modo a não restar nenhum na região do Oeste Catarinense. Algumas localidades (linhas, distritos e, também, municípios) conservam, ainda hoje, o nome faxinal, mas não há outro resquício daquela forma de vida organizada com base no coletivismo. No vizinho estado do Paraná, ao contrário, os faxinais não só se mantiveram mas também são acionados como identidade sociocultural na luta por direitos territoriais. Estão organizados na Articulação Puxirão dos Povos Faxinalenses e contam com o apoio de diversas instituições, dentre as quais a Pastoral da Terra ${ }^{4}$ (SOUZA, 2009).

O que resta das práticas de redistribuição, na região do estudo, são as festas de "adoar". Podemos citar a Festa do Senhor Divino ou Festa do Divino (MARCON, 2003), visto que em algumas regiões ela desapareceu completamente. Foi revitalizada na Linha Almeida, interior de Chapecó, onde os moradores dispunham dos instrumentos, como o estandarte. Originalmente, a bandeira percorria as moradas arrecadando gêneros alimentícios para a festa. Outra festa de resistência é a de São Sebastião, que ocorre nas linhas Barra dos Índios e Barra de São Pedro. As doações são centralizadas e, por ocasião da solenidade, redistribuídas aos participantes, independentemente da doação. Esse estilo de festa tem razão de ser na centralização e redistribuição, como figura na análise de Polanyi (1980) $)^{5}$. Durante o almoço, é anunciado que circulará a lista a ser subscrita com as doações para a próxima festa. Esta lista poderá contemplar alimentos e bebidas (não alcoólicas) e propiciará a participação de maior número de pessoas com menor poder de renda.

Polanyi (1980) aponta pistas para estudar a função redistributiva, como o caso das festas caboclas. A redistribuição e a reciprocidade são pilares da economia pré-capitalista, na qual a economia encontra-se "embebida" nas demais relações sociais e não autônoma como na sociedade capitalista. Na lógica tradicional dessa população, a terra não era mercadoria passível de compra e venda. A colonização introduz e generaliza a lógica mercantilista, o que contribui para provocar o fosso entre os grupos.

Em contraste com a perspectiva dos posseiros, para quem o habitus indicava que a terra pertencia a Deus ou ao Brasil, a colonização instaura um novo modo de produzir, de gerenciar, de pensar, isto é, um novo habitus (BOURDIEU, 1972). A apropriação privada da terra resulta na perda dos territórios ocupados, na desestruturação do modo de vida e na instauração de clivagem entre o colono e a população local.

As colonizadoras eram arregimentadoras de agricultores do Rio Grande do Sul, chamados colonos, que compravam parcelas em áreas de floresta por preço menor que os praticados naquele Estado. Quando se pergunta a um agricultor que imigrou nas décadas de 1930 ou 1940 do século passado o que o trouxe para o Oeste Catarinense, a resposta mais frequente é que veio em busca de terras baratas e de águas. A carência das águas, no Rio Grande do Sul, é algo recorrente nas narrativas dos colonos. 
Outro traço comum desses imigrantes é a identidade étnica. Eram, na quase totalidade, descendentes de alemães, italianos e poloneses. Compravam as terras como estratégia de reprodução social camponesa. No discurso dos colonos encontramos alguns marcos fundantes, tais como a figura do herói fundador, o ascetismo justificando a sociodiceia e, eventualmente, a reconversão de trajetória de agricultor em comerciante ou congênere. Cabe ressaltarmos que as companhias colonizadoras concorriam entre si para vender o maior número de lotes.

No período anterior à colonização, a extração da erva-mate era atividade exclusiva da população cabocla, praticada em dois períodos: o da safra, no inverno, e o da safrinha, no verão. Embora houvesse regulamentação para a extração, essa nem sempre era acompanhada de fiscalização, em face da amplidão das "manchas de ervais". A rigor, a atividade extrativista da erva-mate é uma faina familiar, necessitando do concurso das formas plenas e marginais (TEPICHT, 1973). Considerando que não havia quem comprasse a erva "crua", aquele foi o tempo da "erva sapecada". Após o processo de desidratação, que compreendia a secagem dos maços de erva pelo calor do fogo, com remanejamento constante, a fim de evitar que se queimasse em excesso, a matéria-prima era enviada ao soque de beneficiamento.

Com a colonização, houve uma divisão étnica do trabalho na atividade ervateira. Os colonizadores que se dedicaram a essa atividade passaram a construir engenhos mecânicos, os chamados barbaquás, recolhendo a erva crua colhida pelos tarefeiros. Os meios de transporte contribuíram para tal, circulando longas distâncias para arrecadar os volumes desbastados.

Se os barbaquás estão nas mãos dos colonizadores, os caboclos, por sua vez, quando expropriados das terras, também foram desapropriados dos ervais anteriormente disponíveis. Perderam a autonomia e tornaram-se extratores, recebendo por tarefa, ou seja, por arroba extraída. Atualmente, a extração da erva-mate é um ofício étnico situado na mais baixa hierarquia das atividades laborativas. Nada estranho, portanto, que ocorram denúncias de trabalho escravo entre extratores de erva-mate.

$\mathrm{O}$ corte da erva-mate exigia força física para os grandes deslocamentos no meio da mata, destreza no manuseio do facão e habilidades para sobreviver em condições precárias de alojamento. Eram comuns os acidentes com os instrumentos de trabalho e com animais peçonhentos, além das quedas do alto das árvores. Os conflitos (brigas) eram outro fator de risco frequente.

No início do século passado, a ervamate era levada ao Rio Grande do Sul, Paraná e Argentina. Para a divisa seca de Dionísio Cerqueira, era carregada em bruacas de couro conduzidas por mulas, que retornavam trazendo víveres. Parte era escoada pela estrada de ferro São Paulo-Rio Grande, pelo município de Cruzeiro (atual Joaçaba). Pelo rio Uruguai, desciam para o país vizinho embarcações chamadas piráguas. Estas eram feitas de madeira de lei, bem vedadas, de "feitio de caixão", para comportar o produto (MALAN, 1919).

A erva-mate poderia ser vendida in natura ou industrializada. A industrialização era realizada em instalações rudimentares, consistindo em carijos e barbaquás, onde a erva era sapecada (submetida a altas temperaturas para perder a umidade) e posteriormente socada. A socagem era realizada em monjolos e pilões movidos por roda d'água ou roda "tocada" por bois. E esse processamento da ervamate agregava-lhe valor de comercialização ${ }^{6}$.

Bavaresco (2005, p. 60), com base em Linhares (1969), aponta que a industrialização de erva-mate foi desestimulada pela majoração do imposto de importação cobrado pela Argentina para o produto processado: "Assim, a proteção para a indústria argentina proporcionava um aumento nas exportações da erva cancheada [seca e desgalhada, mas não socada], bem como do contrabando". Nas décadas de 1920 e 1930, a indústria argentina da erva-mate prosperou, em detrimento da produção ervateira no Oeste Catarinense, onde remanesceu a atividade extrativista.

Com o início da colonização da região Oeste de Santa Catarina por agricultores oriundos do Rio Grande do Sul, diversificam-se as atividades laborais e econômicas. Os colonos passam a 
exercer, nos novos núcleos coloniais, trabalhos agrícolas associados à criação de animais, em regime econômico de subsistência. Alguns desempenhavam ofícios variados, como a pequena indústria (produção de banha, embutidos, queijos, vinhos), além de alguma manufatura doméstica. Era relevante, no contexto de ocupação de terras inóspitas, conhecer os ofícios de marceneiro e ferreiro, entre outros.

Outras atividades desempenhadas pelos colonos foram a derrubada de matas e a abertura de estradas. Esse trabalho poderia ser exercido em benefício da própria família ou a serviço das companhias colonizadoras, como forma de pagamento pela terra. Os colonizadores dedicavamse à venda da madeira e foram os primeiros madeireiros da região.

Conforme foi escasseando a mata nas proximidades do rio Uruguai, o corte da madeira passou a ser feito por caboclos, conhecedores da mata densa. As toras eram arrastadas até afluentes do rio Uruguai, utilizados como hidrovias (BAVARESCO, 2005).

As toras de madeiras nobres eram arrastadas por bois até o rio Uruguai, amarradas em forma de balsas e, nas épocas chuvosas em que as águas do rio subiam ao nível esperado, levadas rio abaixo até a Argentina. A condução da balsa era feita pelo "prático", profissional experiente, conhecedor do rio e das corredeiras. $\mathrm{O}$ percurso rio abaixo era perigoso e aconteciam acidentes fatais.

Conforme Bavaresco (2005), a mão de obra para as madeireiras era oriunda majoritariamente do Rio Grande do Sul. Registra-se, igualmente, a presença da população cabocla nesse ofício.

Quando se estabeleceram serrarias na região, parte da madeira era serrada em pranchas com medidas estabelecidas pelo mercado consumidor. Neste caso, as balsas eram amarradas com arame, em substituição ao cipó usualmente utilizado para fixar as toras. A necessidade de esperar as cheias do rio para comercializar a madeira fazia desta uma atividade sazonal.

A madeira foi fonte de riqueza regional (BELLANI, 1991). A atividade extrativa foi amplamente explorada, inicialmente escoada pela água, em formações de balsas feitas de toras ou pranchas amarradas com cipó e arame. Os balseiros aguardavam as estações chuvosas para aproveitar as cheias do rio Uruguai e, assim, conduzir as balsas até a bacia do Prata.

Com a implantação de serrarias no interior do território, à medida que a colonização avançava, a madeira beneficiada foi fartamente utilizada na região, que carecia de casas, galpões e outras benfeitorias. A atividade madeireira deixou marcas como a devastação de florestas, sem a preocupação de reflorestamento. Nos últimos anos a paisagem apresentou alteração com a introdução de exemplares exóticas como eucalipto e pinus, para fins industriais e para a construção civil. A indústria moveleira surge como polo econômico relevante no Oeste Catarinense, atendendo ao mercado regional e encontrando demanda na exportação.

Os produtos cultivados nas colônias, comumente, eram: milho, mandioca, batata, feijão, arroz, trigo, cana-de-açúcar e fumo. As propriedades dispunham de pomar e horta para abastecimento das famílias. Parte da produção era destinada à criação de porcos e galinhas, pois não havia forma de escoar o excedente aos mercados consumidores.

Os núcleos coloniais geralmente dispunham de um armazém. A mediação com os espaços de trocas comerciais era feita pelo comerciante ou vendista, geralmente um colono oriundo do Rio Grande do Sul que já tinha experiência com comércio. "O colono criava uma dependência junto ao comerciante - econômica, por não saber quanto valia seu produto, e cultural, pois o comerciante passou a ser uma pessoa entendida, que sabia mais" (BAVARESCO, 2005, p. 128).

Nessa época, as mercadorias que abasteciam a região Oeste de Santa Catarina chegavam de trem a Joaçaba, provenientes de São Paulo e de Curitiba. A distribuição aos armazéns dos núcleos coloniais era feita em lombo de mulas, nos cargueiros de couro (bruacas) e em carroças. Havia, ainda, mascates que faziam o comércio nas colônias, percorrendo o Noroeste do Rio Grande do Sul e o Oeste de Santa Catarina.

As mulheres constituem o "outro" da e na economia de mercado. Por muito tempo, foram 
representadas, "expressadas" e externalizadas. Não obstante o trabalho paritário, eram-lhes disponibilizados os produtos de menor monta, as chamadas "miudezas" (DORIGON; RENK, 2011), tais como ovos, queijo, leite, verduras, ou seja, recursos periféricos na propriedade, cuja renda era destinada à aquisição de ingredientes domésticos, aviamentos para costura etc. Correlata à designação da economia de periferia na propriedade, inseria-se a subalternização que consistia em ser nominada pelo nome do marido. Até muito recentemente, resquício desse hábito figurou nas placas indicativas das agroindústrias integradoras nas entradas das propriedades rurais, nas quais constavam somente os nomes dos "chefes de família", desconsiderando que essa figura legal foi extinta pela Constituição de 1988. Ser nominada pelo sobrenome do marido não era tudo: muitas mulheres não possuíam título eleitoral e, em seus documentos, a qualificação era "do lar" em vez de agricultora; assim, elas não tinham direito à aposentadoria como trabalhadoras rurais.

As estruturas do mundo rural mudaram. As mulheres lutaram pela conquista de direitos. A Constituição de 1988 assegura a paridade homem-mulher, rural e urbano, a Aposentadoria Especial ao Trabalhador Rural, se forem cumpridas as exigências formais. $O$ recurso entrante da aposentadoria permitiu às mulheres adquirir gêneros alimentícios e outros itens no mercado, o que, por sua vez, implementou o giro de recursos financeiros na primeira quinzena de cada mês nos pequenos municípios, predominantemente rurais. Estruturalmente, as mulheres empoderam-se e passam a circular em outros espaços para além da propriedade rural.

Há, contudo, a outra face de Jano: as miudezas são surrupiadas. A integração vertical produz ovos em maior quantidade e menor preço, não compensando mais dedicar-se a essa atividade. Além disso, se a propriedade conta com aviário, não pode manter aves caipiras. O leite e o queijo, que foram recursos da economia feminina, passaram à esfera masculina. Melhor dito, a atividade leiteira é hoje essencialmente gerenciada pelos homens. As precárias instalações do passado são reordenadas para incorporar novas tecnologias compatíveis com status da atividade na propriedade. O queijo que ainda é produzido vem sofrendo restrições de comercialização nos últimos anos. O serviço de vigilância sanitária interdita o modo tradicional de produção, à base de leite cru. $\mathrm{E}$ as adequações nem sempre são consideradas compensadoras.

\section{Agroindustrialização e integração vertical}

Nas primeiras décadas da imigração de colonos ao Oeste Catarinense, os porcos criados com o excedente da produção agrícola das famílias eram levados vivos, em tropas, para os centros consumidores do Rio Grande do Sul, ou até Joaçaba, onde eram embarcados em trens para São Paulo. Esse comércio com o Sudeste se intensificou na década de 1940.

Em virtude de as terras do Oeste Catarinense serem virgens e de qualidade, de a topografia ser favorável à produção de milho, da construção da estrada de ferro Rio Grande-São Paulo e do crescimento do mercado urbano de São Paulo (em processo de industrialização), a produção de suínos dessa região catarinense concorreu com Minas Gerais e acabou tornando-se, por excelência, a região abastecedora dos frigoríficos instalados em São Paulo. (ESPÍNDOLA, 1999, p. 102).

Para os caboclos, no período anterior à colonização e depois desta, o porco foi elemento da economia e da dieta alimentar. A banha, a carne, o torresmo e o toicinho eram ingredientes da culinária. A criação dos animais, no chamado "sistema brasileiro", consistia em dividir as áreas ocupadas em terras de plantar e terras de criar. Estas estavam situadas próximas às moradias, cerca dos cursos d'águas, onde os animais eram mantidos soltos. Esse procedimento era observado entre a população que "fazia para o gasto", ou seja, em uma perspectiva de subsistência. A roça ficava mais afastada da casa.

Com a instalação de frigoríficos e fábricas de banha, uma fração da população autóctone 
sucessora de fazendeiros em declínio econômico podia valer-se das "safras" (CORREA, 1970). Estas eram praticadas em áreas de baixa densidade demográfica e consistiam em cultivar milho e abóbora e, em seguida, soltar os porcos na área para que "criassem por si". Ressaltamos que esta técnica também foi utilizada ocasionalmente por descendentes de alemães e italianos. Anteriormente à safra, houve o "sistema do porco alçado", estudado por Roberto Lobato Correa (1970) no sudoeste do Paraná, cuja propriedade pode estender-se ao locus deste estudo. O suíno era criado solto em extensas áreas de mata, ocupando em média cinco hectares de terra por cabeça. O principal alimento dos animais eram a semente da imbuia e o pinhão.

A safra permitia aumentar a densidade de suínos por hectare, passando a quatro cabeças/ha, e era atividade econômica intercalada com a safra da erva-mate. Ou seja, não consistia em atividade de tempo integral. Os animais eram tropeados para outro safrista que poderia encerrar o ciclo de engorda, se fosse o caso, ou para comerciante que, por sua vez, os repassava ao intermediário com destino a frigoríficos instalados na região ou até a estrada de ferro.

Em outros locais de áreas mais concorridas, em municípios de população cabocla, ocorreu o procedimento de criação confinada em mangueirões de duas quartas. "A base da alimentação eram frutos silvestres e também abóboras, batata doce, milho e mandioca. No inverno, os porcos eram conduzidos para os pinheirais devido à abundância de pinhões" (CEOM, 2008, p. 29).

O espaço onde são criados os suínos diz a posição e a condição do caboclo, diferenciando internamente a população local. Aquele que cria o animal solto, próximo de casa, o faz para sua dieta alimentar. Aquele que visa a objetivos econômicos pode fazê-lo em cercado, no caso do mangueirão ou da safra.

A introdução da colonização, em regime de pequena propriedade, conflita com a criação cabocla, seja a do "sistema brasileiro", a safra ou o mangueirão. É proscrita a prática dos caboclos de criar os animais soltos perto da casa. Instaura-se o "regime das cercas". Os animais, confinados, são criados pertos de casa. Os bovinos são alojados nos potreiros, com suas cercas, e os suínos são instalados nas pocilgas, os chamados chiqueirões, evitando que adentrassem nas lavouras. Em alguns casos, permitia-se a soltura dos suínos próximos aos chiqueiros, em área de tapumes, onde eram alimentados.

Inicialmente, nas pocilgas eram confinados os chamados porcos comuns, geralmente de pelagem escura e fornecedores de banha. Esta, além de ingrediente da dieta diária dos agricultores, era fonte de renda. Nos anos iniciais da colonização, os depoimentos apontam a dificuldade em escoar a banha e falta de compradores. O plantel de cada agricultor era motivo de orgulho e constava do roteiro de visitação entre os vizinhos. Se a estética arquitetônica do chiqueirão de madeira bruta não era para ostentação, o conteúdo poderia sê-lo. A força de trabalho da propriedade rural confluía para o sustento da maior fonte econômica da propriedade. Milho, mandioca, abóbora, aveia, cana-de-açúcar e outros cultivares serviam de alimento aos animais.

A modernização da agricultura e a demanda da indústria de carne, em expansão na região, introduzem o suíno de carne, em detrimento do suíno de banha. O óleo vegetal substitui esse ingrediente da culinária, tornando-a dispensável e de baixa demanda no mercado. Segundo Olinger (2006), Attilio Fontana, do grupo Sadia, importou dos Estados Unidos e da Europa matrizes de suíno tipo carne das raças Duroc-Jersey, Landrace, Hampshire, Large White. Outras experiências de importação ocorriam na região, como registra Jungblut (2006), ao atribuir ao Padre Oscar Puhl, em 1962, a criação de um posto de suinocultura em Sede Capela, Itapiranga, criando suínos das raças acima mencionadas e vendendo-os aos agricultores.

No hiato até a consolidação da integração vertical, coube à Acaresc (atual Epagri) a orientação para a substituição dos antigos chiqueirões e a introdução dos novos preceitos de manejo. Paulatinamente, ocorreu o processo de substituição do suíno tipo banha pelo suíno tipo carne, sendo implantada a integração vertical e iniciando-se o processo de concentração da suinocultura e de exclusão de suinocultores menos capitalizados. 
Um dos traços evidentes da mudança na suinocultura são as terminologias adotadas: chiqueirão passou a ser sinônimo de atraso; adotou-se a nomenclatura "pocilga", mais adequada à modernização. $\mathrm{O}$ habitante deixou de ser $\mathrm{o}$ porco e passaou a ser o suíno. A arquitetura do estabelecimento, a dieta alimentar e as prescrições de higienização no desenvolvimento do plantel seguem os parâmetros da empresa integradora (agroindústria).

A relevância da produção de suínos na economia mercantil do Oeste Catarinense ensejou a instalação de frigoríficos na região. A indústria Perdigão S.A. foi fundada por Saul Brandalise em Videira, no vale do rio do Peixe, em 1934. Em 1944, Attilio Fontana, italiano oriundo do Rio Grande do Sul e estabelecido como comerciante em Joaçaba, liderou a fundação da Sadia (Sociedade Anônima Indústria e Comércio Concórdia), empresa que contava com 27 acionistas. Seguiram-se as fundações da Chapecó Industrial (1952), Frigorífico Seara (1956), Sociedade Anônima Frigorífica de Itapiranga (SAFRITA) (1962), Indústria e Comércio Marafon Ltda. (1956) sucedida pela Cooperativa Central Oeste Catarinense (1969) e pelo Frigorífico São Carlos (1975) ${ }^{7}$.

O surgimento das agroindústrias no Oeste de Santa Catarina teve influência do processo de industrialização por que passava o país. A tecnologia, nessa área, era proveniente dos Estados Unidos da América e da Itália. Também havia a participação de recursos estatais, via BNDE (federal) e PROCAPE (estadual) (ESPÍNDOLA, 1999; GOULARTI FILHO, 2007).

Em boa medida, a explicação para o bom desempenho dos grandes frigoríficos em Santa Catarina reside no longo processo de modernização conservadora e nas benesses da política agrícola (incluindo subsídios e financiamentos. [...] A criação do Bando de Desenvolvimento do Estado de Santa Catarina (BDE, depois BESC) e do Banco Regional de Desenvolvimento do Extremo Sul (BRDE), ambos em 1962, inaugurou uma nova fase do sistema de crédito no estado (SCHMITZ, 1991; FONSECA, 1988). O eixo central do sistema financeiro se deslocou do crédito ao consumo para o crédito ao investimento de longo prazo. Após o reordenamento do $\mathrm{BDE}$, ocorrido no final da década de 1960, foram criados outros mecanismos de fomento, como o Fundesc, o Procape e o Prodec, a Agência de Fomento do Estado de Santa Catarina (Badesc), todos com um propósito claro: fomentar e incentivar a indústria e a agroindústria catarinense. (GOULARTI FILHO, 2010, p. 49).

Uma dificuldade enfrentada para a manutenção dos níveis de produção industrial era a oscilação no fornecimento da matéria-prima. Neste aspecto, foi decisiva a iniciativa de Attilio Fontana ao introduzir o modelo de integração vertical de produção animal para o abastecimento dos frigoríficos, que já era utilizado na Europa e na América do Norte. A experiência pioneira consistiu na produção intensiva de suínos na Fazenda Santa Luzia, em Concórdia, em 1951, e estendeu-se à produção de aves, em 1960, no mesmo município (ESPÍNDOLA, 1999).

A integração vertical vem sendo estudada por diferentes áreas do conhecimento, tendo-se em conta a complexidade das relações socioeconômicas que enseja. É, ainda hoje, o arranjo produtivo dominante no ramo agroindustrial catarinense de processamento de carnes e derivados, beneficiandose da prevalência do modelo agrário de pequenas unidades de produção familiar.

Esse modelo organizacional é conhecido no setor como integração, no qual o suinocultor se insere na cadeia produtiva vinculado a uma agroindústria de abate e processamento que, geralmente, também coordena os elos a montante da produção primária, sobretudo na fabricação de ração. A integração predomina na suinocultura da região Sul do País, mas cresce nas demais regiões acompanhando a expansão geográfica das agroindústrias líderes. Entretanto, há uma multiplicidade de formas organizacionais coexistindo, com um expressivo número de suinocultores não integrados, denominados no setor de independentes. (MIELE; WAQUIL, 2007, p. 818). 
A estrutura da integração vertical pressupõe obrigações de parte do integrador e do integrado. Ao primeiro compete fornecer os animais para reprodução, criação ou terminação (conforme o caso), a ração (no todo ou em parte), a assistência técnica e a atenção veterinária. Ao último compete o cuidado dos animais, o que implica aglutinar os esforços familiares no manejo e vigilância. Tratase de trabalho intensivo, sem limite de jornada diária, nem direito a descanso semanal. Não há remuneração do trabalho, mas pagamento por lote de animais entregues à agroindústria. $\mathrm{O}$ preço do lote varia conforme a cotação do produto no mercado internacional e são abatidos os custos dos insumos fornecidos pela empresa integradora.

Nas últimas décadas, vem ocorrendo a diminuição na quantidade de produtores rurais integrados, paralelamente ao aumento da capacidade dos contingentes observados. Assim, por exemplo, cresceu o tamanho médio dos aviários, permitindo às empresas os benefícios de escala na produção, além de vantagens logísticas ${ }^{8}$. A contrapartida é o empobrecimento e o deslocamento dos numerosos produtores desligados, aspecto maior do panorama de intensos fluxos migratórios desde o Oeste o Meio-Oeste para os municípios litorâneos, sobretudo dirigidos à Grande Florianópolis (LINS; MATTEI, 2010)ํ․

\section{Meio ambiente do trabalho}

As agroindústrias, na sua constituição, primavam preferencialmente pela mão de obra de filhos de agricultores, pelo ethos do trabalho introjetado e por reproduzirem, na empresa, o padrão hierárquico da subordinação familiar. De outro lado, gerações de trabalhadores se autoenalteceram como integrantes de tal empresa, expressando sentimento de pertença. No entanto, hábitos e habitus mudam. O observado nos últimos anos é a recusa do trabalhador urbano a exercer atividades de abate e corte nas agroindústrias de carnes e derivados. Há relatos de lesões físicas, tais como Lesão por Esforço Repetitivo (LER), Distúrbio Osteomuscular Relacionado ao Trabalho (DORT) e de sofrimento psíquico, como depressão relacionada a quadro de dor crônica. O documentário Carne e Osso ${ }^{10}$ registra o mal-estar que afeta trabalhadores do segmento de produção de carnes e derivados na região. Chapecó conta com duas associações de lesionados do trabalho, criadas para a defesa de direitos dos trabalhadores que contraem enfermidades laborais.

A escassez de mão de obra local gerou mudança na estratégia de recrutamento. Para suprir as vagas no chão de fábrica da agroindústria, inicialmente, foram arregimentados indígenas Kaingang e Guarani de diversas aldeias do norte do Rio Grande do Sul e do Oeste de Santa Catarina. São dezenas de ônibus precários que se deslocam a Chapecó e a outras cidades transportando trabalhadores indígenas para as agroindústrias. Mais intensamente a partir de 2010, foram recrutados também haitianos e senegaleses como trabalhadores do setor de abate e corte da agroindústria. No fábrica, são muitos os elementos que contribuem para o agravamento das condições do meio ambiente de trabalho: velocidade excessiva da nória, insuficiência de pausas para repor as forças físicas, temperatura muito baixa, ruído, pressão constante para aumentar a produtividade, entre outros fatores, geram desgastes aos trabalhadores.

O meio ambiente do trabalho da área rural afeta, de modo semelhante, os corpos dos agricultores. As extensas jornadas da atividade agrícola e as múltiplas atividades que têm sob sua responsabilidade levam os trabalhadores ao adoecimento. Com frequência queixam-se de dores lombares e nos membros, dores de cabeça e malestar gástrico (que dificilmente associam à aplicação de veneno, embora essa relação seja clara do ponto de vista das pesquisas em saúde). Os acidentes de trabalho são frequentes, apesar de subnotificados.

É significativo o número de trabalhadores, principalmente do segmento feminino, que alegam ter dificuldades para dormir e sofrer de "doença dos nervos", recorrendo a ansiolíticos e antidepressivos. O sofrimento se faz presente nas situações críticas, como na ocorrência de intempéries e de problemas na família. 


\section{Considerações finais}

Neste texto abordamos a região, relacionalmente, sob o prisma da construção histórica. Uma perspectiva substantiva não abarca as múltiplas faces e recortes que se faz e de que é feita uma determinada região. As narrativas das quais nos valemos pautaram-se nos aspectos multidimensionais, mostrando como o Oeste Catarinense foi se construindo.

Nessas narrativas um dos fios condutores foi o trabalho, que adquire o status de idioma de etnicidade, nos diferentes contextos históricos. Trabalho do tropeiro, trabalho do serrano, trabalho do ervateiro, trabalho nas fazendas de criar, trabalho nas balsas, trabalho nas colônias, trabalho na agroindústria. Este último caso, de modo especial, remete-nos ao chão de fábrica, por onde passaram filhos de colonos que, depois de décadas, recusam a atividade. $\mathrm{O}$ setor agroindustrial busca nas aldeias os índios Guarani e Kaingang para estes serem operários. Mais recentemente, haitianos e senegaleses realizam o ofício recusado pelos oestinos. A recusa de alguns, pela adversidade nas condições de trabalho, é a empregabilidade de outros. Por quanto tempo?

O habitus na relação com a terra tem posição polarizada entre caboclos e indígenas, de um lado, e os colonos descendentes de europeus, de outro. Tomando-se o caso dos caboclos, a concepção de terra é de que esta não é mercadoria. Como explicita Polanyi (1980), a Economia de Mercado é apenas uma das concepções possíveis. $\mathrm{O}$ que existe é um modo de vida imerso nas relações sociais. Logo, vicejam relações de reciprocidade, práticas de redistribuição, tais como as chamadas "festas de adoar", diferentes daquelas trazidas pelos agricultores vindos do Rio Grande do Sul.

A colonização representou uma fricção interétnica, respaldada por novo esquema mental, novos habitus, e resultou na expropriação dos recursos naturais, dentre os quais a terra, criando uma clivagem de etnias. Instaura-se uma divisão étnica do trabalho na região.

Também no grupo de colonizadores instauram-se hierarquias e clivagens entre agricultores, comerciantes e bodegueiros que, mais tarde, são reproduzidas entre agroindústrias e integrados, intensificando-se em relação àqueles excluídos da suinocultura e da avicultura. No interior do grupo familiar, na frágil economia doméstica, as mulheres gerenciavam o recurso advindo das "miudezas", ocupando posição subalterna. Perdem esse recurso na medida em que a lucratividade aumenta, a exemplo da atividade leiteira, que se tornou masculina.

Falar do Oeste Catarinense pressupõe situar o momento a que nos referimos, em face das transformações por que passou e por que passa. Não se posse deixar de assinalar diacriticamente o empoderamento das mulheres que, ao contrário de algumas décadas atrás, conquistaram seus direitos civis e políticos e ocupam espaços em ONGs e instituições sociais. Já em relações aos jovens, fatia considerável deixa a área rural em busca de outros projetos de vida. As fronteiras entre rural e urbano tornam-se esgarçadas, vaticinando que rural não é necessariamente agrícola.

\section{Notas}

1 Exemplificando essa dificuldade, observa-se que os próprios critérios institucionais adotados pelos governos federal e estadual produzem diferentes morfologias: "Em 1940, o Instituto Brasileiro de Geografia e Estatística (IBGE) dividiu o Estado de Santa Catarina em oito zonas fisiográficas, a região Oeste Catarinense sendo entendida como Zona do Oeste. Novos estudos em 1966, pelo Conselho Nacional de Geografia (CNG), estabeleceram, em 1968, que Santa Catarina seria agrupada em 16 microrregiões. O Projeto Catarinense de Desenvolvimento (PCD) baseou-se em 13 microrregiões. Assim, o Oeste Catarinense passaria a compreender duas microrregiões: Oeste e Extremo Oeste de Santa Catarina." (BAVARESCO, 2005, p. 35-36).

2 Interpretamos a migração forçada dos indígenas como um processo de confinamento territorial.

$3 \mathrm{O}$ termo embeddedness vem sendo traduzido ao português como "imersão" e "incrustação".

4 No Paraná, a secretaria do Meio Ambiente e Recursos Hídricos tem competência legal de reconhecer, com fundamento na Constituição Federal de 1988, na Convenção 169 da Organização Internacional do Trabalho e a Convenção da Biodiversidade, além de leis e decretos, os faxinais como Área Especial de Uso Regulamentado (Aresur). O Instituto Ambiental do Paraná (IAP) apontou a existência de 44 faxinais, mas 
a Articulação Puxirão dos Povos Faxinalenses indica número maior. Até o momento, foram reconhecidos, formalmente, 22 áreas.

5 A arrecadação de alimentos para festa e sua partilha em comum estaria no polo da redistribuição, exemplo estudado por Polanyi (1980) e presente nas sociedades arcaicas. Em uma festa convencional, como aquelas dos colonizadores, para arrecadar fundos para igrejas ou escolas, o alimento é arrecadado e depois vendido.

6 O surgimento das ervateiras com equipamentos modernos, notadamente a partir da segunda metade do século XX, praticamente fez desaparecer na região a prática de produzir erva-mate pelo método antigo, ressalvadas pequenas produções para o autoconsumo.

$7 \mathrm{O}$ estudo detalhado da agroindustrialização do Oeste catarinense realizado por Espíndola (1999) é a principal referência dos dados ora apresentados.

8 Acerca desse fenômeno, recomenda-se a seguinte leitura: TESTA et al. O desenvolvimento sustentável no Oeste Catarinense (Proposta para Discussão). Florianópolis: EPAGRI, 1996.

9 Parte da mão de obra é absorvida pelas granjas instaladas pelas próprias agroindústrias e por empresas agrícolas, em regime de assalariamento.

10 Documentário realizado pela ONG Repórter Brasil e dirigido por Caio Cavechini e Carlos Juliano Barros, em 2011.

\section{Referências}

BAVARESCO, Paulo Ricardo. Ciclos econômicos regionais: modernização e empobrecimento o Extremo Oeste catarinense. Chapecó: Argos, 2005.

BELLANI, Eli Maria. Madeira, balsas e balseiros no Rio Uruguai: o processo de colonização do velho municipio de Chapeco (1917/1950). 1991. 327 f. Dissertação (Mestrado em História), Universidade Federal de Santa Catarina, Florianópolis, 1991.

BOURDIEU, Pierre. Esquisse d'une theorie de la pratique. Geneve: Droz, 1972.

CENTRO DE MEMÓRIA DO OESTE DE SANTA CATARINA (CEOM). Inventário da cultura imaterial cabocla no oeste de Santa Catarina. Chapecó: Argos, 2008.

CORREA, Roberto Lobato. O sudoeste paranaense antes da colonização. Revista Brasileira de Geografia. Rio de Janeiro, Ano 32 (1), 1970, p. 87-98.
DORIGON, Clóvis; RENK, Arlene. Técnicas e métodos tradicionais de processamento de produtos coloniais: de miudezas de colonos pobres aos mercados de qualidade diferenciada. Revista de Economia Agrícola (Online), v. 58, p. 101-113, 2011.

ESPÍNDOLA, Carlos José. As agroindústrias no Brasil: o caso sadia. Chapecó: Grifos, 1999.

GOULARTI FILHO, Alcides. Formação econômica de Santa Catarina: uma tentativa de síntese. In: MATTEI, L.; LINS, H. N. A socieconomia catarinense - cenários e perspectivas no início do século XXI. Chapecó: Argos, 2010. p. 29-62.

\section{JUNGBLUT, Roque. Documentário histórico de} Porto Novo. São Miguel do Oeste: Arco Iris Gráfica e Editora, 2000.

LINS, Hoyedo Nunes; MATTEI, Lauro. Liberalização econômica e reestruturação produtiva: reflexos em Santa Catarina no limiar do novo século. In: MATTEI, L.; LINS, H. N. A socieconomia catarinense - cenários e perspectivas no início do século XXI. Chapecó: Argos, 2010. p. 109-155.

MALAN, Alfredo. O Passo do Goio-En. Revista de Instituto Histórico e Geográfico e Santa Catharina, Volume VII, 3․ Trimestre, Typ. Da Escola de Aprendizes Artífices, 1919, p.272-280.

MARCON, Telmo. Memória, história e cultura. Chapecó: Argos, 2003.

MAUSS, Marcel. Sociologia e Antropologia. São Paulo: Cosac Naify, 2003.

MIELE, Marcelo; WAQUIL, Paulo D. Estrutura e dinâmica dos contratos na suinocultura de Santa Catarina: um estudo de casos múltiplos. Estudos Econômicos, São Paulo, v. 37, n. 4, p. 817-847, out./ dez. 2007.

OLINGER, Glauco. 50 anos de extensão rural: breve histórico do serviço de extensão rural no estado de Santa Catarina 1956-2006. Florianópolis: Epagri, 2006. 
POLANYI, Kar. A grande Transformação - As origens da nossa época. Rio de Janeiro: Campus, 1980.

RENK, Arlene. Sociodicéia às avessas. Chapecó: Grifos, 2000.

A luta da erva: um ofício étnico da nação brasileira no oeste catarinense. 2. ed. rev. Chapecó: Argos, 2006.

SOUZA, Roberto Martins de. Mapeamento social dos faxinais no Paraná. In: ALMEIDA, Alfredo
Wagner Berno de; SOUZA, Roberto Martins de (Org.). Terras de Faxinais. Manaus: Edições da Universidade Estadual do Amazonas, 2009. p. 113-130.

TEPICHT, Jersey. Marxisme et agriculture: le paysan polonnais. Paris: Armand Collin, 1973.

TESTA, Vilson Marcos.; NADAL, Raul de; MIOR, Luiz Carlos; BALDISSERA, Ivan Tadeu. O desenvolvimento sustentável no Oeste Catarinense (Proposta para Discussão). Florianópolis: EPAGRI, 1996. 